\title{
Medical Disorders of Pregnancy in Patients at Dhaka National Medical Institute Hospital
}

\author{
Mst. Shahana Pervin *1, Mst. Monowara Begum ${ }^{2}$, Jahanara Rahman ${ }^{3}$
}

\section{Abstract}

Introduction: Hypertensive disorders are the commonest complications during pregnancy responsible for maternal and foetal mortality and morbidity. The aim of the study was to determine the magnitude of percentage of disorders in admitted pregnant women. A retrospective study was done to determine the pattern of disorders during pregnancy among the admitted pregnant women National Medical Institute Hospital. This study was done during January 2017 to December 2017 at Dhaka National Medical Institute Hospital. Materials and Methods: 3276 pregnant women admitted had medical disorders (406) with 12.39\% at the age of reproduction (20-35 years). Results: The commonest disorders were hypertensive disease of pregnancy $(45.32 \%)$, urinary tract infection (14.78\%), gestational diabetic mellitus $(10.84 \%)$, anaemia $(7.39 \%)$, bronchial asthma (6.40\%) respiratory infectious conditions (5.42\%), viral infections (3.94\%), thyroid disorder (3.45\%), and cardiac disease (2.45\%). Conclusion: Hypertensive disorder is the most common medical disorder of pregnancy followed by urinary tract infection, gestational diabetic mellitus, anaemia, bronchial asthma respiratory infectious conditions, viral infections, thyroid disorder and cardiac disease in order.

Keywords: Medical disorders, Hypertension, Pregnancy, Viral infections, Thyroid disorder, Cardiac disease.

Number of Tables: 04; Number of Figures: 04; Number of References: 23; Number of Correspondence: 05.

*1. Corresponding Author:

Dr. Mst. Shahana Pervin

Associate Professor (cc)

Department of Gynae and Obst

Dhaka National Medical College \& Hospital, Dhaka.

2. Dr. Mst. Monowara Begum

Senior Medical Officer

Department of Gynae and Obs

Dhaka National Medical College \& Hospital, Dhaka.

3. Dr. Jahanara Rahman

Professor (cc)

Department of Gynae and Obst

Dhaka National Medical College \& Hospital, Dhaka.

\section{Introduction}

Pregnancy is a normal condition which may be complicated by many medical disorders ${ }^{1}$. Changes occurring during pregnancy are required for the successful outcome of pregnant women and foetus. Medical disorders may interfere with these adaptations and complicate the pregnancy and foetus $^{2}$. In some conditions, pregnancy is contraindicated and early termination may be needed for the health of mother and foetus. While Twenty percent are the result of pre-existing conditions that are exacerbated by pregnancy or its management while ${ }^{3}$ eighty percent of maternal mortality is due to the direct causes. It is to said that three quarters of mothers died from pre-existing medical or mental health problems and two thirds of them had died from medical and mental health problems ${ }^{4}$.
Maternal and foetal mortality and morbidity is still higher in developing countries in comparison to the developed countries but over past years maternal mortality have decreased worldwide nations. The burden of non-communicable disease like heart disease, chronic respiratory disease and diabetes are increasing in number in the period of pregnancy ${ }^{5}$. Medical disorders during pregnancy previously had a much worse outcome in terms of both maternal and foetal health. With the improvement and intervention of different new medical instruments may cause advancement in all the sectors especially, obstetric anaesthesia and paediatrics, more fruitful outcome can be achieved even in pregnancies with the older age group $^{6}$. In a study done in Africa, the incidence of medical disorders in pregnant women was $15 \%$. This study aims to find out the magnitude and types of medical disorders during pregnancy at Dhaka National Medical Institute Hospital.

\section{Materials \& Methods}

This is a retrospective study done in Dhaka National Medical Institute Hospital. It is a tertiary referral institute and maternity and general hospital. Information were taken from the admission registered record of the Gynae and Obs. department of hospital from January 2017 to December 2017. Number of gravid, parity, gestational age at presentation and type of disorder were recorded for the pregnancies with medical disorders.

\section{Results}

During the study period out of 3276 pregnant women admitted, 406 had medical disorders. The age ranged from 16 to 47 years with the mean age of 31.5 years. Peak incidence $(68.96 \%, 280)$ was seen at the age of reproduction (20-35 years) (Table-II) while 31.04\% (126) were in the extremes of ages (figure-2). Table-1 showing that a total number of 3276 pregnant women admitted and 406 had medical disorders. 
Table-I: Admitted pregnant women and percentage of medical disorders.

\begin{tabular}{|l|l|l|}
\hline Total number & Number of medical disorders & Percentage \\
\hline 3276 & 406 & $12.39 \%$ \\
\hline
\end{tabular}

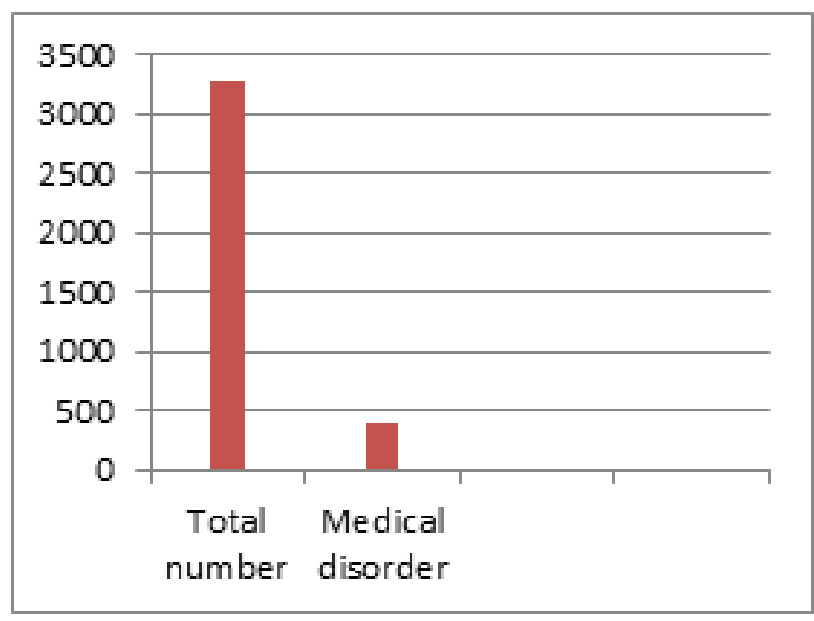

Figure-1: Total number and medical disorders of pregnancy.

Table-II showing peak and lowest incidence of age groups.

Table -II: Age distribution.

\begin{tabular}{|l|l|l|l|}
\hline Total number & $\mathbf{1 5 - 2 0}$ & $\mathbf{2 0 - 3 5}$ & $>\mathbf{3 5}$ \\
\hline 406 & 56 & 336 & 14 \\
\hline
\end{tabular}

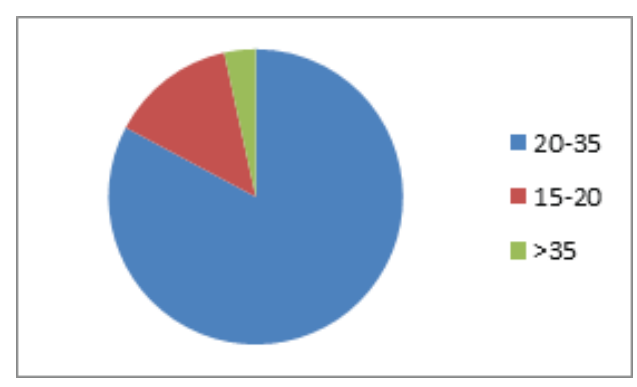

Figure -2: Gestational age at the time of admission.

Hypertensive disorders were the commonest $(68.2 \%, 184)$ medical cause for admission (table-III) among the pregnant women (figure 3). Majority of them had pre-eclampsia (112), (table-IV) then gestational hypertension (60) while chronic hypertension was seen in 08 women and a few (four) of them were admitted with eclampsia. Pre-existing chronic hypertension was seen among 08 women and two of them had superimposed pre-eclampsia. Renal and urinary tract disorders were the second (60) leading cause for admission (figure 3), (Table-III). Urinary tract infections (45) and pyelonephritis (15) accounted for about $14.78 \%$ of all the medical disorders during the study period (table-III). About four percent of women were admitted with viral infectious diseases and majority (14) among them had HBsAg positive status (figure 3 and table III). Two women each had viral fever at the time of admission. Fourteen $(3.45 \%)$ pregnant women had hypothyroidism while Graves's disease was seen in one woman during the study period. Respiratory disorders were seen among (22) women among whom upper respiratory tract infection (16) was the commonest one followed by GDM (table-III). Among the forty-four cases of diabetes with pregnancy two-third of them had gestational diabetes mellitus while rest had overt diabetes (table III). Acute gastro-enteritis necessitating admission was found among one pregnant woman. Anaemia was seen in thirty cases while two cases each had epilepsy and dermatological problem. Cardiac disease was seen in 10 (table-III) women at admission and one woman had psychiatric disorder during the study period.

Table-III: Types of medical disorders in pregnancy.

\begin{tabular}{|l|l|l|}
\hline Hypertension & 184 & $45.32 \%$ \\
\hline UTI & 60 & $14.78 \%$ \\
\hline GDM & 44 & $10.84 \%$ \\
\hline Anaemia & 30 & $7.39 \%$ \\
\hline Bronchial asthma & 26 & $6.40 \%$ \\
\hline RTI & 22 & $5.42 \%$ \\
\hline Viral & 16 & $3.94 \%$ \\
\hline Thyroid & 14 & $3.46 \%$ \\
\hline Cardiac & 10 & $2.45 \%$ \\
\hline
\end{tabular}

Figure -3 shows distribution of medical disorder in pregnancy

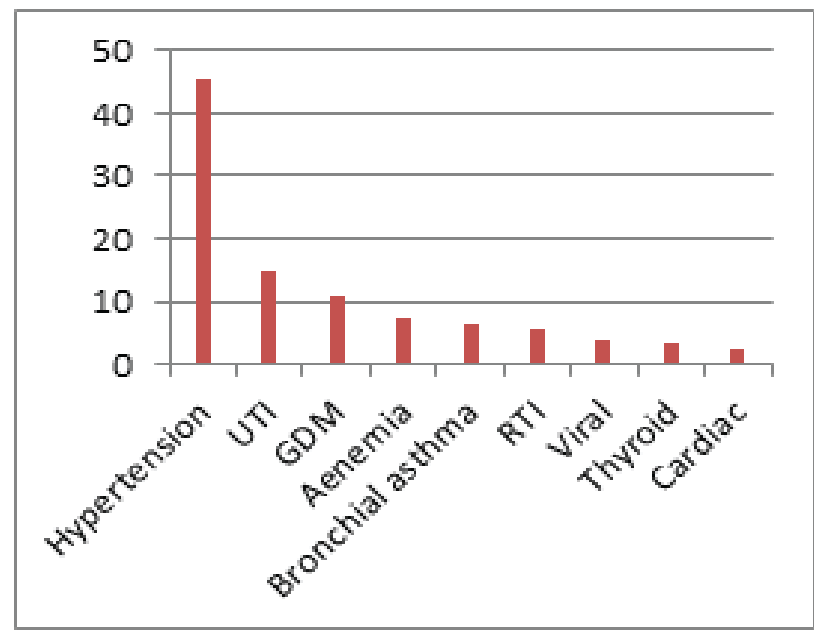

Figure-3: Distribution of medical disorders of pregnancy. 
Table-IV shows subtypes of hypertension.

Table -IV: Subtypes of hypertension.

\begin{tabular}{|l|l|}
\hline Pre-Eclampsia & 112 \\
\hline Gestational & 60 \\
\hline Chronic hypertension & 08 \\
\hline Eclampsia & 04 \\
\hline
\end{tabular}

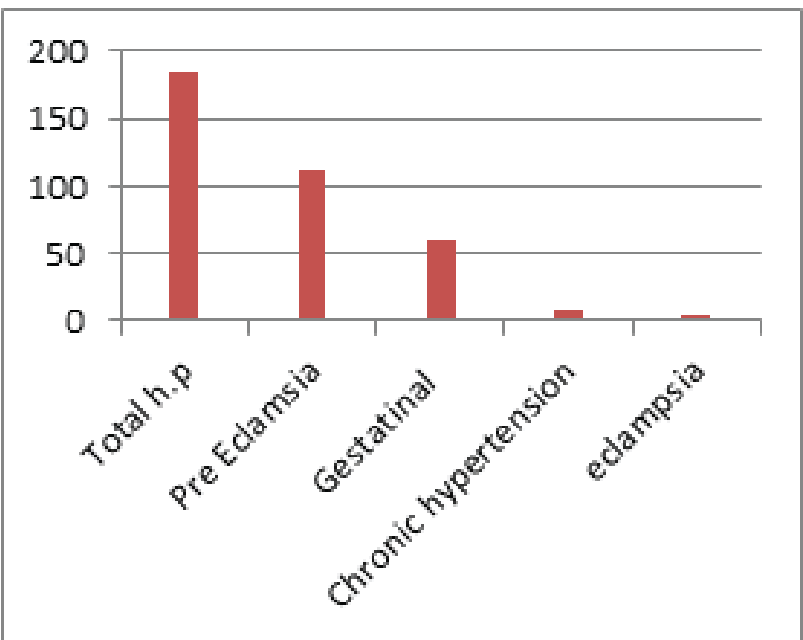

Figure-4: Subtypes of hypertensive disorders of pregnancy.

\section{Discussion}

The incidence of medical disorders with pregnancy in this study was $12.39 \%$ compared to the study done by Rozati et $\mathrm{al}^{7}$. In this study, hypertensive disorders was the commonest disorder while in the Nigerian study hypertensive ${ }^{9}$ disorder was second to the malarial which could be due to higher prevalence of malaria in Nigeria ${ }^{10}$. In a multi-centric study done in China, severe pre-eclampsia ${ }^{11}$ was the commonest while in this study UTI was second to the gestational hypertension ${ }^{12}$. Eclampsia was the least common one among the hypertensive disorders similar to other studies ${ }^{13}$. Urinary tract infection is the second most common medical disorder in this study which is comparable to the Nigerian study ${ }^{14}$. This signifies the necessity to screen the pregnant women for asymptomatic bacteriuria ${ }^{15}$. Higher incidence of pyelonephritis $(3.2 \%)$ in pregnancy is found in this study whereas a six years database study done in Jamaica found 102 cases $(0.7 \% \text { of deliveries })^{16}$. Viral infection is more common while hepatitis B infection is found to be most common type among the infectious medical disorders ${ }^{17}$. A five-year record a hospital in India where out of $136(0.3 \%) \mathrm{HBsAg}$ positive cases only 32 pregnant women were recorded as positive ${ }^{18}$. Higher incidences of hypothyroidism is seen in this study which is similar to two year study done in 1000 pregnant women where 116 had thyroid disorders ${ }^{19}$. Anaemia necessitating admission was found in 30 cases in this study which is less compared to the other studies which had included all severities of anemia $^{20}$. In a six years study done in Iran, they found 50 cases of pregnancy with epilepsy ${ }^{21}$. Cardiac disease during pregnancy in this study is much less compared to a study done in India, where 59 cardiac cases out of 7053 deliveries was found ${ }^{22}$. Intra-hepatic cholestasis of pregnancy was seen in one case at the time of admission which is comparable to the average incidence (less than one percent) in Asian population ${ }^{23}$.

\section{Conclusion and recommendation}

Hypertensive disorder is predominant medical disorder of pregnancy followed by urinary tract infection, gestational diabetic mellitus, anaemia, bronchial asthma respiratory infectious conditions, viral infections, thyroid disorder and cardiac disease in order.

Hypertensive disorders in pregnancy are the most common medical disorder followed by renal and urinary tract infections Infectious diseases and endocrine disorders also affect pregnancy. Endocrine disorders and viral infections are also common group of medical disorder. Pregnancy management, therefore, requires multidisciplinary approach for better outcome.

As the size of the population in the current study was small and it was limited to one hospital so it could not represent the actual picture of medical disorders of pregnancy of whole population of Bangladesh. Therefore, large scale studies of longer duration are necessary.

\section{Conflict of Interest: None.}

\section{Acknowledgement}

I must express gratitude to Professor Dr. Arzumanth Ara, head department of Gynae \& Obst, Dhaka National College \& Hospital, Dhaka, for allowing me to work under her on such topic. I must express respect to Professor Dr. Jahanara Rahman, department of Gynae \&Obst, Dhaka National College \&Hospital for her valuable suggestions and kind help during my study. My sincere thanks to Dr. Monowara Begum, senior medical officer, Gynae. \& Obst department, Dhaka National College \&Hospital for her active help during the period of the study. I am thankful to my husband Professor Dr. Md. Nazrul Islam, for his constant inspiration, he provided me and pain suffered during this study. It would be incomplete on part of my acknowledgement if I do not remember those patients whose sincere co-operation helpful here to complete the study. Finally I thanks my sons Md Sayed Ahsan, Md Abid Ahsan and my daughter Nazifa Nushin Nabila for their assistance in computer typing of this article.

\section{References}

1. Steven G. Gabble, Jennifer R. Niebyl, Joe Ligh Simson. Obstetrics, Normal and Problem Pregnancies. 4th edition. Churchil livingstone; 2002: 945.

2. David H. Nichols, Mosby. Gynaecological and Obstetric surgery. London; 1993: 541.

3. Alka Kriplani, Roya Rozati. Gynaecology and Infertility. First edition. Jaypee Brothers; 2002: 12. 
4. Alan H. Decherny Lauren Nathan, Newyork, Lange. CURRENT Diagnosis and Treatment Obstetrics and Gynaecology. 11th edition. 2013: 454.

5. D K James, P .J.Steer C P Weinu B Gonil. High Risk pregnancy.

W B Saunders. 2nd edition. 1999: 61.

6. N. Baker. Obstetrics by Ten Teachers

Philips. 18th edition. U.K.: Book Power; 2006:179-199.

7. Edited by Michel de Swiet. Basic Science in Obstetrics and Gynaecology.

3rd edition. Churchil livingstone; 2002: 233-263.

https://doi.org/10.1007/s006060200075

8. Edited by Harald Konar, Pralhad Kusilagi. Medical Disorder in Pregnancy- An Update.

Jaypee Brothers; 2001:47-290.

https://doi.org/10.1353/cul.2001.0021

9. F. Gary Cunningham, Norman F. Gant

Kenneth J, Leveno, Larry C. Gilstrap iii, John C. Hauth, Katharine D. Wenstrom. William's Obstetrics. 21st edition. 2001: 230.

10. Reduction of maternal mortality: a joint WHO/UNFPA/ UNICEF/World Bank statement. Switzerland :WHO;1999. ISBN 9241561955.

11. Trends in maternal mortality: 1990 to 2013 . Estimates by WHO, UNICEF, UNFPA. The World Bank and the United Nations Population Division; 2014. ISBN 978924 p 150 .

12. Fatemeh M, Nazanin EB. Pregnancy complications and outcomes in women with epilepsy. Open J Obstet Gynecol. 2012; 2: 230.

https://doi.org/10.4236/ojog.2012.23047
13. D C Dutta'sText Book of Obstetrics. 9th Edition. New Delhi; 2018: 245.

14. Prof. Sayeda Nurjahan Bhuiyan. Clinical Guide to Obstetrics and Gynaecology. 6th edition. 2009: 107.

15. Singh $\mathrm{P}$, Khan S, Mittal RK. Anemia during pregnancy in the women of western Nepal. Bali Med J. 2013; 2(1):14-6.

16. Global status report on non-communicable diseases. Italy: WHO; 2010. ISBN 978924068645 8. P 457.

17. Dowhurt's Textbook of Obstetrics and Gynaecology for Postgraduates. Sixth edition. The Blackwell Science Ltd; 2000: 405.

18. Haines \&Taylor. Obstetrical and Gynaecological Pathology. 4th edition, volume-two. Charchill livingstone; 1995: 1215

19. Leon speroff Robert H. Glass Nathan G. Kase, Lippincott Williums \&Wilkins. Clinical Gynaecologic Endocrinology and Infertility. 6th edition. 1999: 857.

20. Edited by Geoffrey Chamberlain. Turnbull's Obstetrics. 2nd edition. Charchill livingstone;1996: 493.

21. Editors Usha Kreshna DK.Tank Shirin daftary. Pregnancy at Risk. Third edition. Jaypee Brothers, Calcatta, India; 1997: 219.

22. Shirish N Daftary Sudip Chakravarti Elsevior. Manual of Obstetrics. Newdelhi; 2003: 213.

23. Professor Dr. C.S. dawn I, Dr. Subata Dawn. Text book of Obstetrics and Neonatology. Dawn Books, Kolkata, india; 2004: 225. 